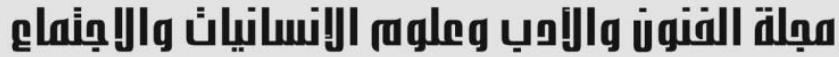

Journal of Arts, Literature, Humanities and Social Sciences www.jalhss.com

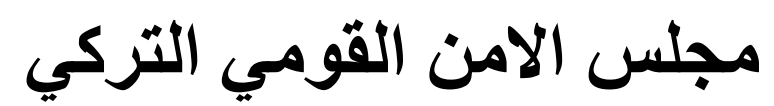

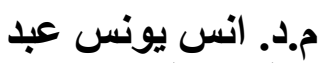

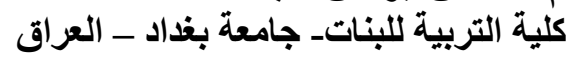

الايميل: admaster73@coeduw.uobaghdad.edu.iq

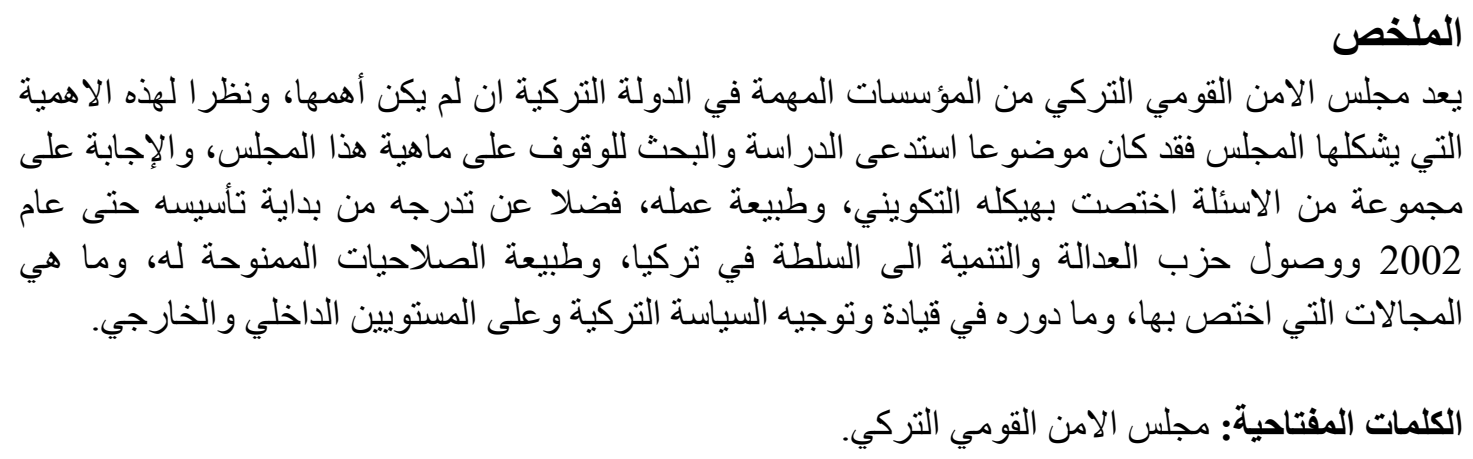

\section{Turkish National Security Council}

\author{
Dr. Anas Younes Abed \\ College of Education for Girls - University of Baghdad - Iraq \\ Email: admaster73@ coeduw.uobaghdad.edu.iq
}

\begin{abstract}
The Turkish National Security Council is one of the important institutions in the Turkish state, if not the most important one, and in view of this importance that the Council constitutes, it was a topic that required study and research to find out what this council is, and to answer a set of questions related to its formative structure, the nature of its work, as well as its gradation The beginning of its establishment until 2002 and the arrival of the Justice and Development Party to power in Turkey, the nature of the powers granted to it, what areas it specializes in, and what is its role in leading and directing Turkish policy at the internal and external levels.
\end{abstract}

Keywords: Turkish National Security Council. 


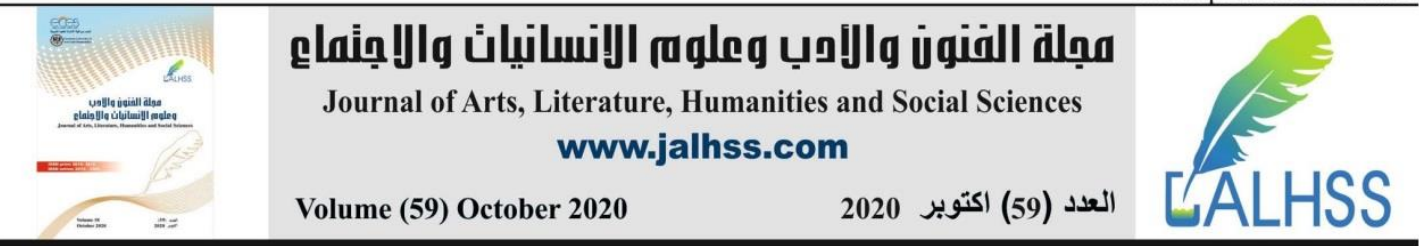

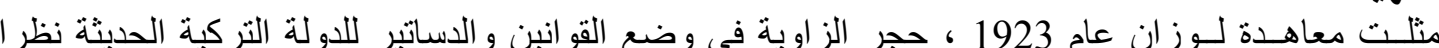

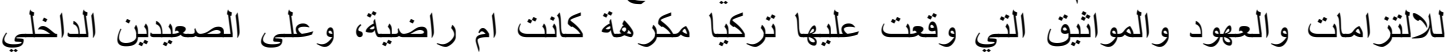

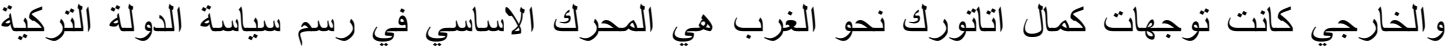

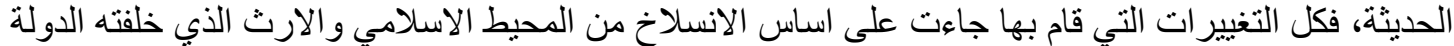

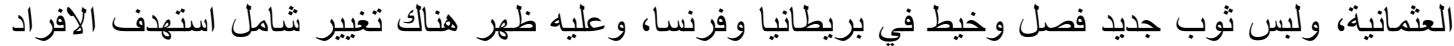
و المؤسسات و المجتمع التركي لتتحول فيه الدولة التئ الى القو مية و العلمانية.

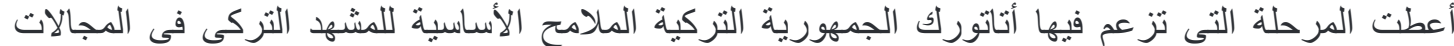

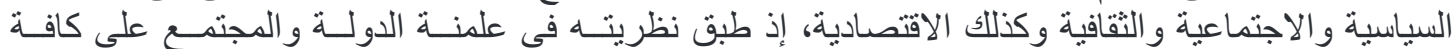

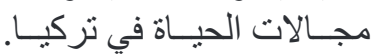

وجاء مجلس الامن القومي التركي (National Security Council Turkey)، ويكتب بالتركي Milli) (Güvenlik Kurulu)

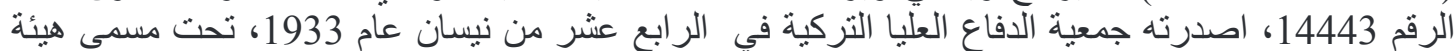

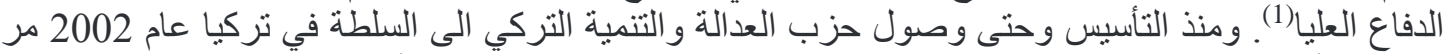

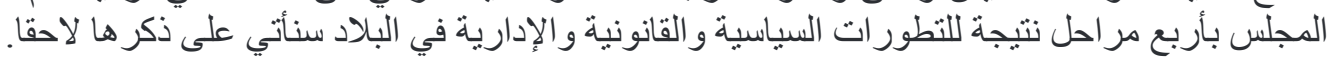

\section{مراحل تطور مجلس الامن القومي التركي}

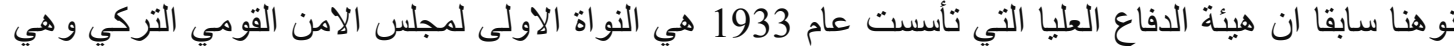

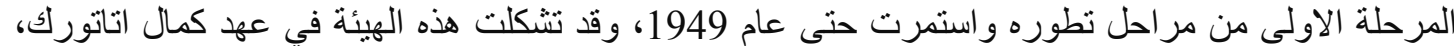
وأثناء تر أس عصدت الاينونو وزارته السادسة (أيار 1931 ـ آذار

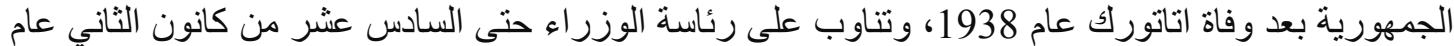

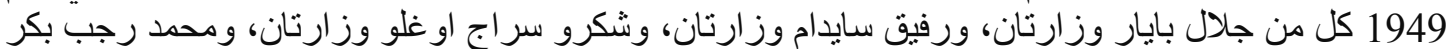

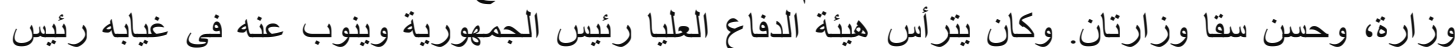

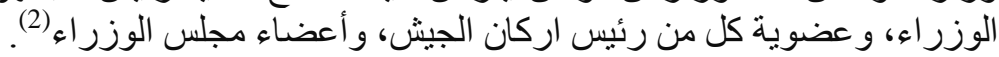

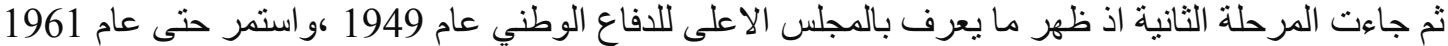

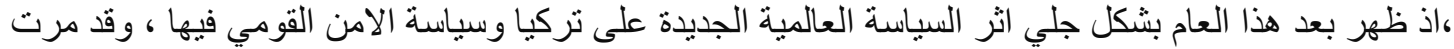

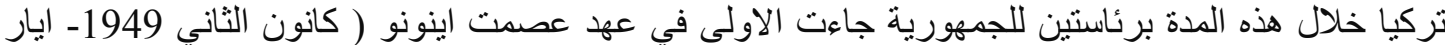

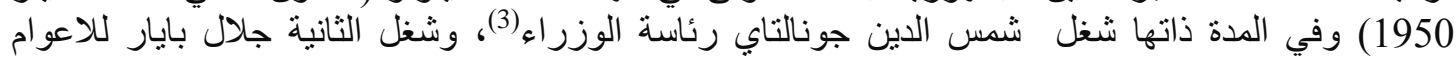

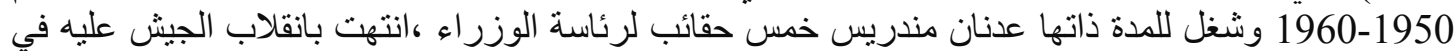

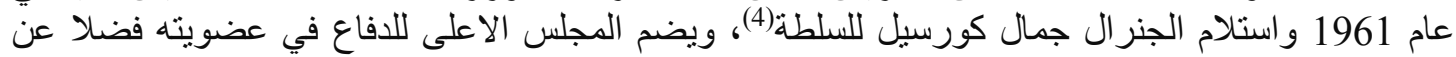

1- Hikmet Özdemir, Rejim ve Asker, (İstanbul, 1993),pp.103-105.

1- Arş. Gör., Milli Güvenlik Kurulu ve Diş Politika Bulut GÜRPINAR. Gebze Yüksek Teknoloji Enstitüsü, Strateji Bölümü,

(Kocaeli,2013),p.77.

3 -حنا عزو بهنان، موقع رئيس الجمهورية في صنع القرار في تركيا، مركز الدراسات الاقليمية، جامعة الموصل، (د،ت)، 


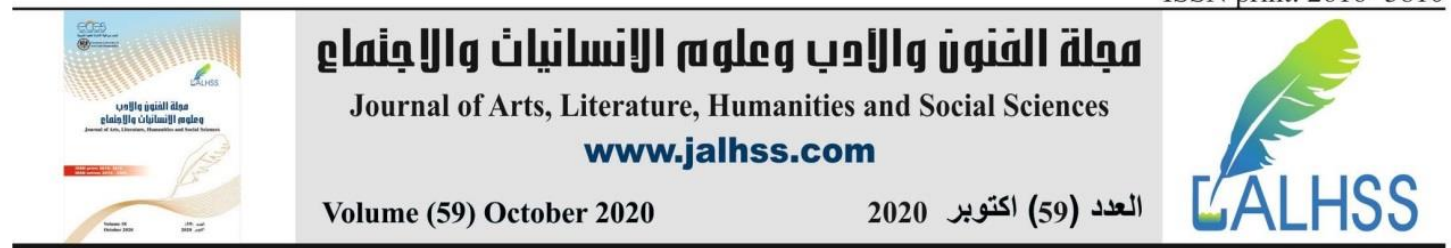

الأعضاء السابقين الذين ذكروا في المرحلة الاولى وزير الدفاع كعضو دائم، فضلا عن منصبه، يضاف اليه عدد من الوزر اء برشحهم مجلس الوزراء (1).

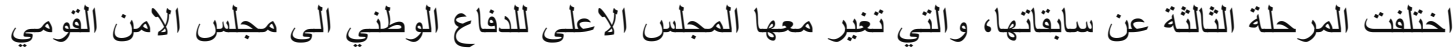

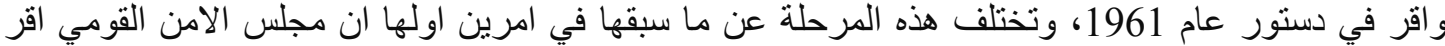

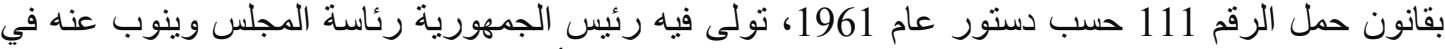

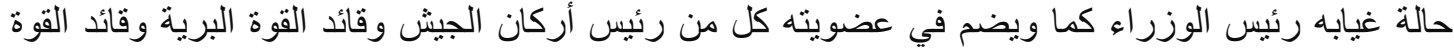

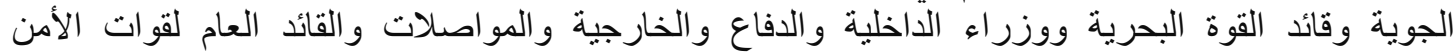

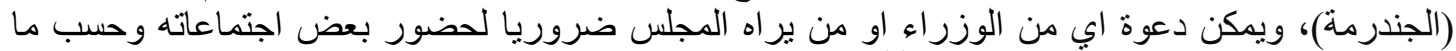

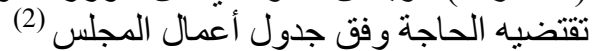

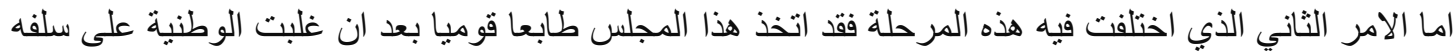

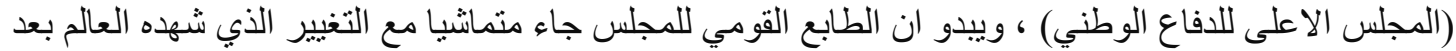

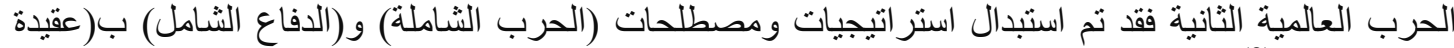

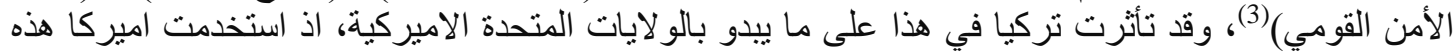

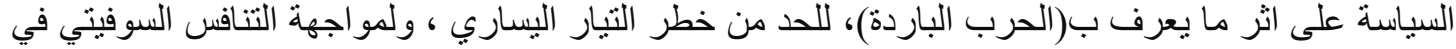

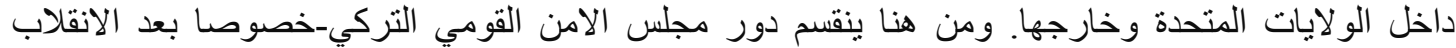

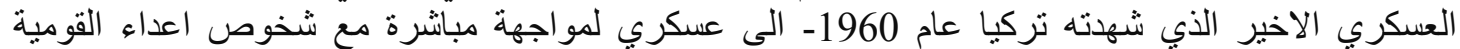

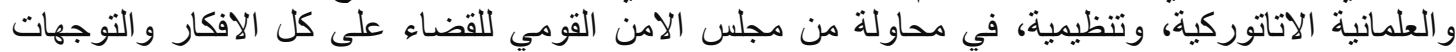

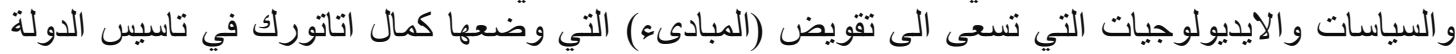

بعد ان أُقر مجلس الامن التركي في دستور عام 1961 ، صر ح مجلس الوزراء التركي في بيان معقبا على مهام

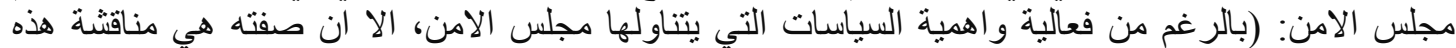

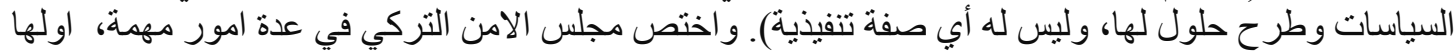

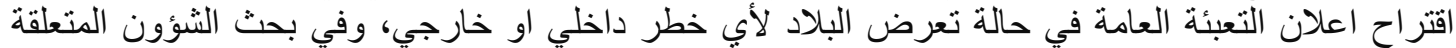

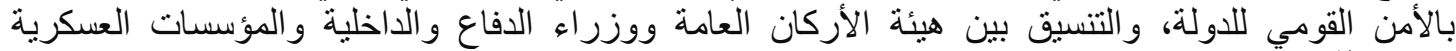

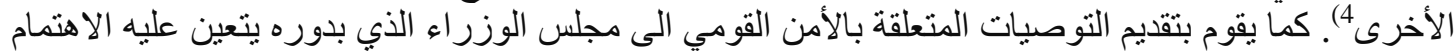

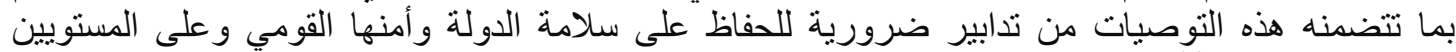

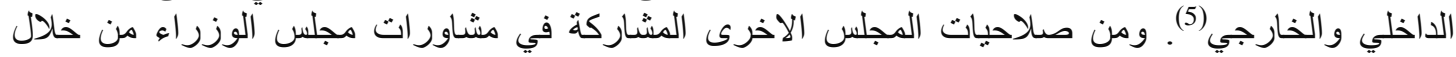

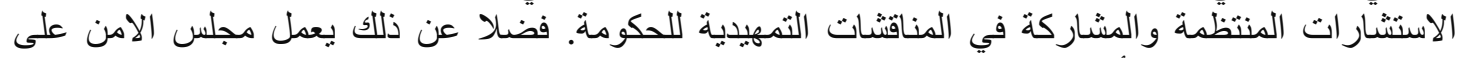

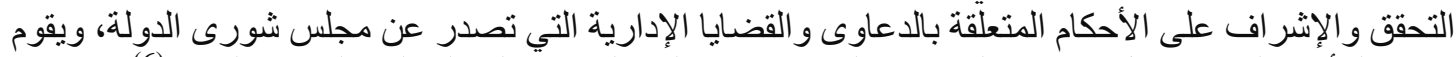

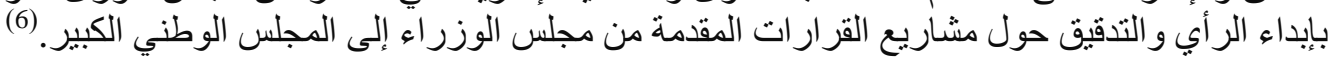

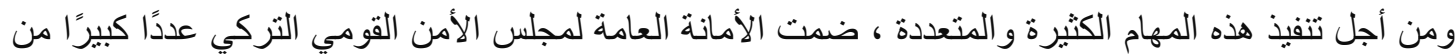

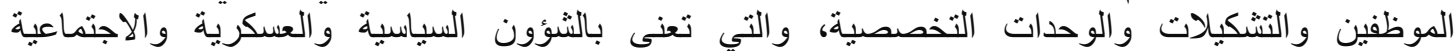

2- Hikmet Özdemir, Op.Cit.,p.106.

- Ibid.,pp.106-107.

4-Muharrem Balcı, MGK ve Demokrasi: Hukuk-Ordu-Siyaset, Yöneliş Yayınevi, (İstanbul 2000).p.39.

1- Muharrem Balc1, Op. Cit.,pp39-40.

5 ـ ـلال يونس الجليلي، قراءة في أفكار النخبة السياسية التركية، (الموصل، 2006)، ص111 - 1114 - 114.

1- Muhsin Batur, Anılar ve Görüşler, "Üç Dönemin Perde Arkası”, (İstanbul, 1985),pp.176-

177. 


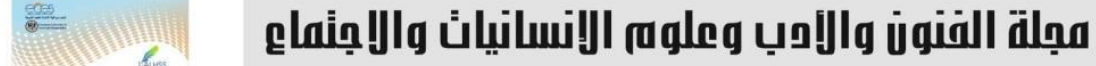 \\ Journal of Arts, Literature, Humanities and Social Sciences www.jalhss.com

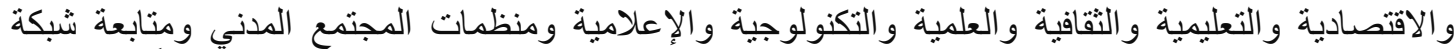

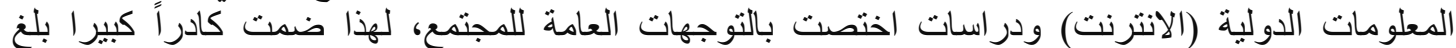

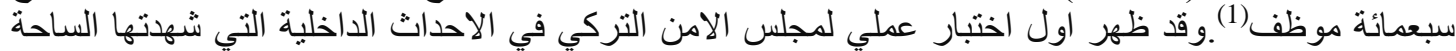

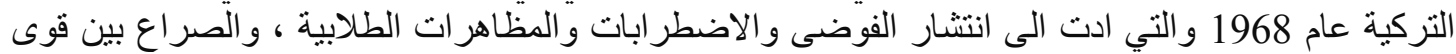

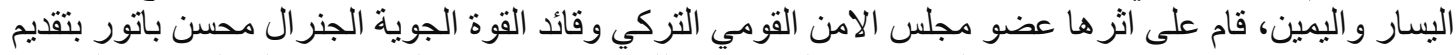

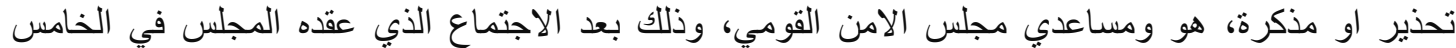

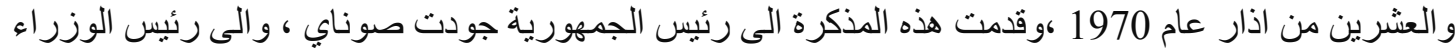

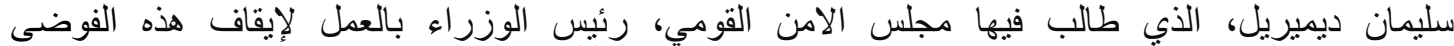

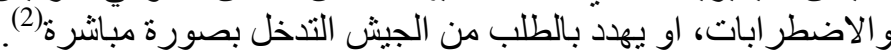

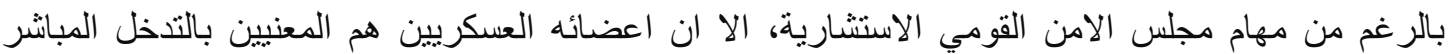

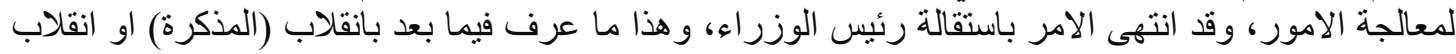

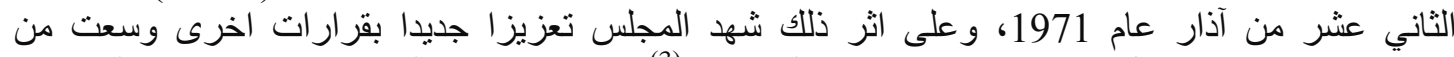

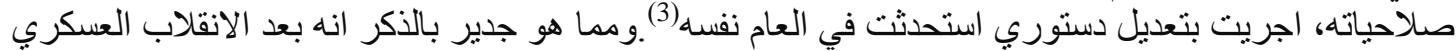

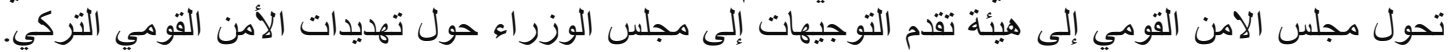

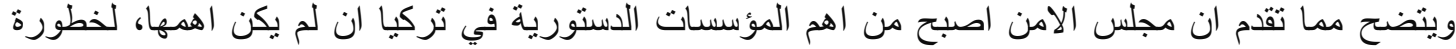

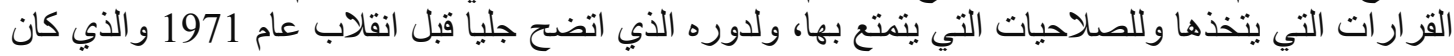
لقرار اته السبب الرئيس في حدوث هذا لإنات الانقلاب.

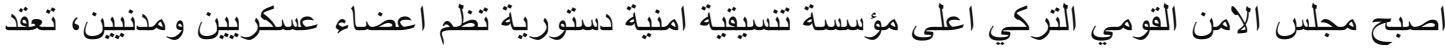

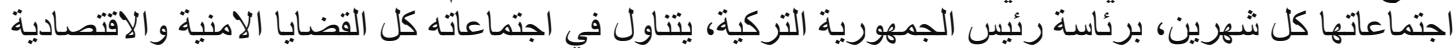

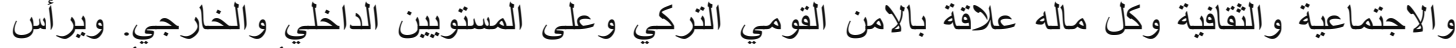

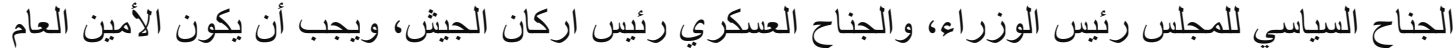

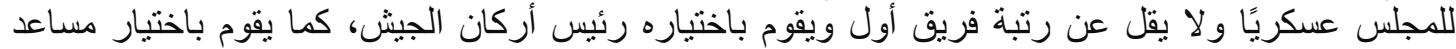

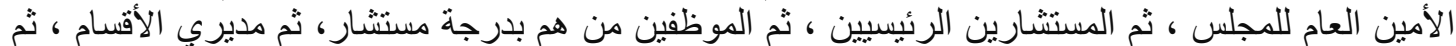

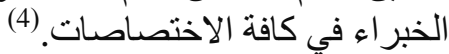

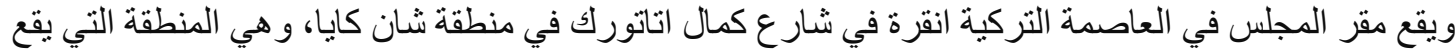

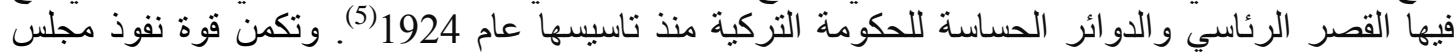

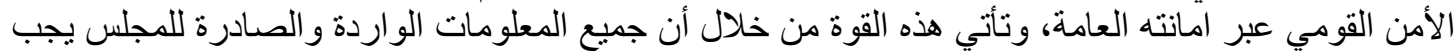

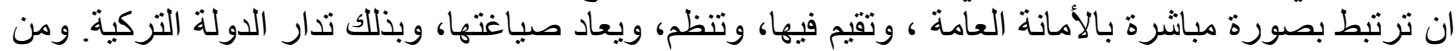

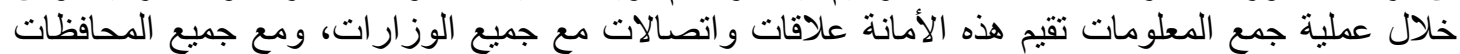

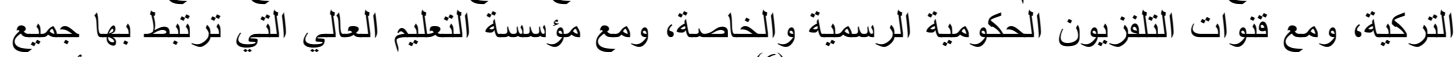

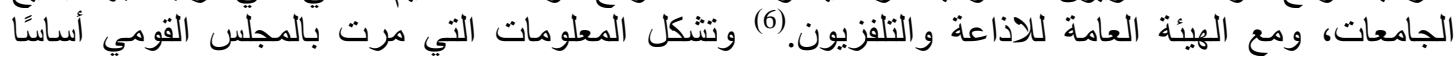
للقرارات التي يتخذها مجلس الوزراء و المجلس النيابي واللجان المنبثقة عنهماً، وللقرار ات التهات المتخذة في مختلف

2-Muharrem Balc1, Op. Cit.,p40.

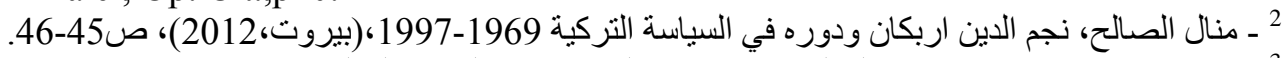

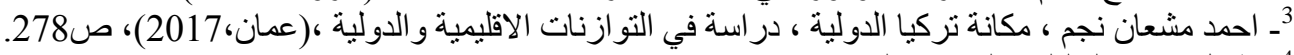

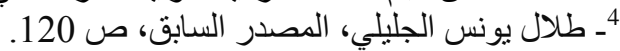

1- Tayfun Akgüner, 1961 Anayasasına Göre Milli Güvenlik Kavramı ve Milli Güvenlik

Kurumu, İstanbul Üniversitesi SBF, 19XX, p.7.

- رضا هلال، السيف و الهلال تركيا من أناتورك إلى أربكان، (القاهرة، 1990)، ص99.6 


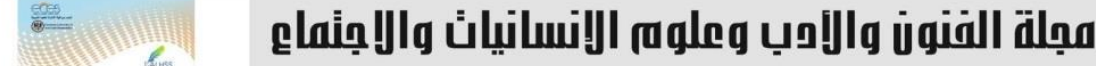

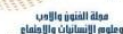 \\ Journal of Arts, Literature, Humanities and Social Sciences www.jalhss.com

الهيئات والمؤسسات.) وبناءا على ما تقام فإن كل شؤون تركيا من النواحي السياسية والعسكرية والأمنية

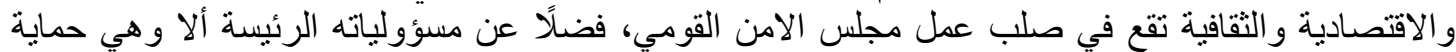

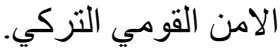

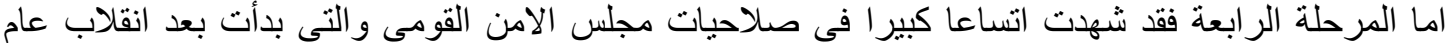

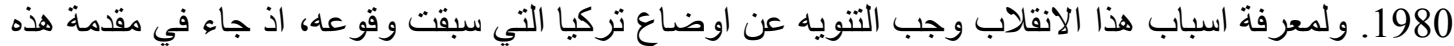

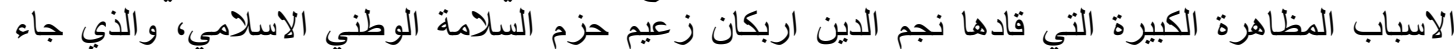

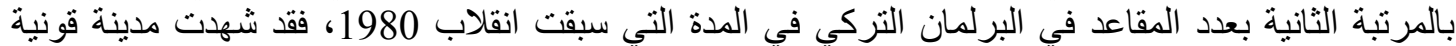

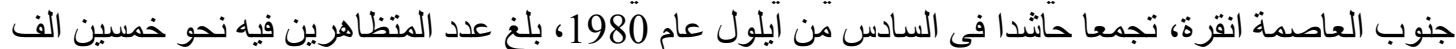

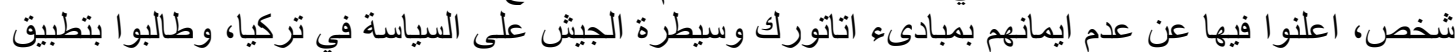

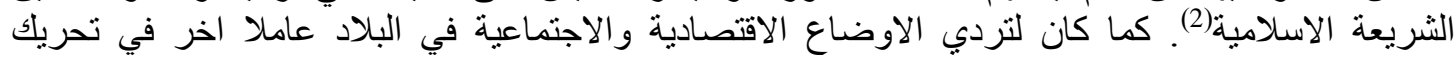

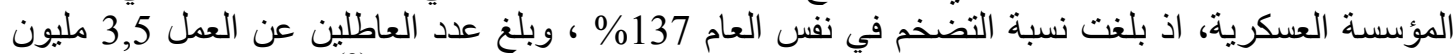
شخص، فضلا عن ازدياد العنف السياسي بين آلقوى المنصار عة على الساحة التركية(3).

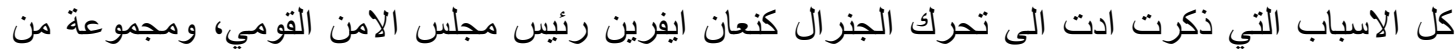

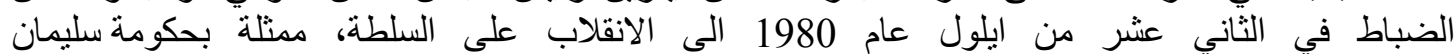

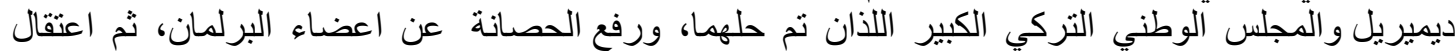

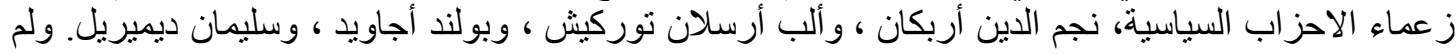

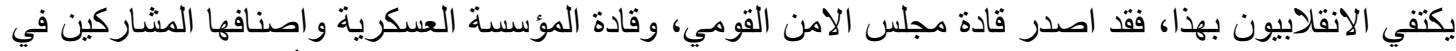

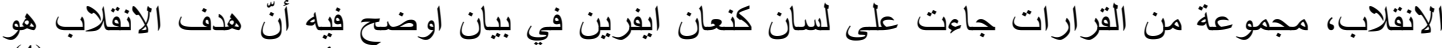

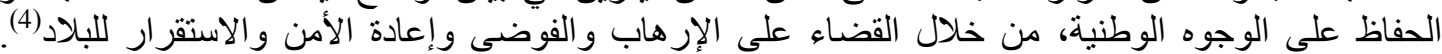

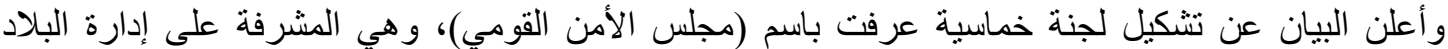

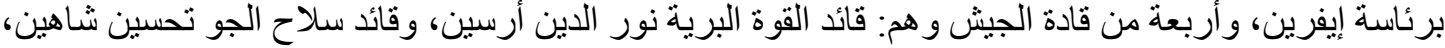

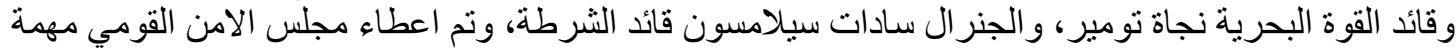

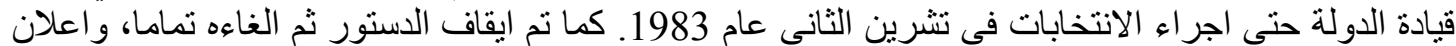

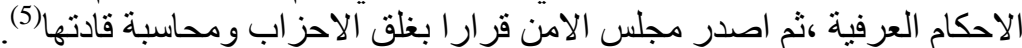

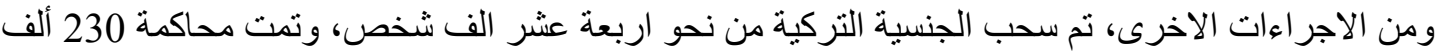

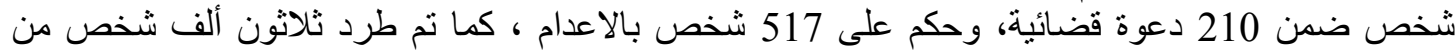

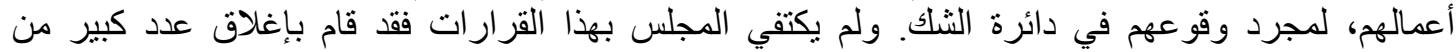

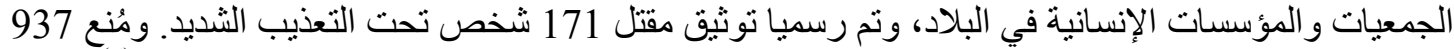

فلم سينمائي من العرض، ولم تتمكن 300 صحيفة من الصدور . وتم اقالة 120 استاذ جامعي من مهامهم (6).

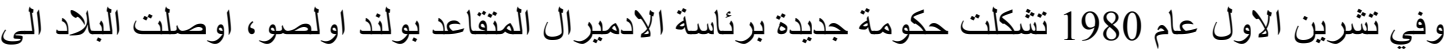

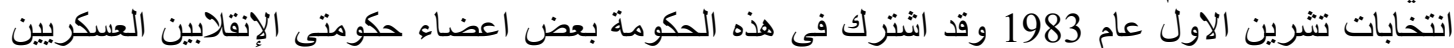

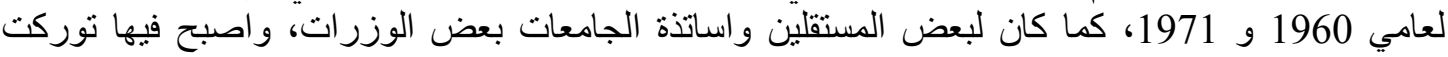

3- Arş. Gör.,Op. Cit.,pp.78-79.

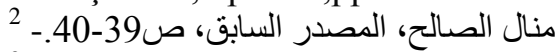

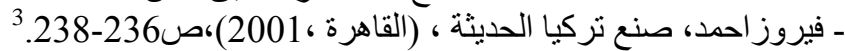

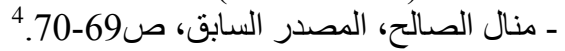

1- Muhsin Batur, Op., Cit.,pp177-178.

ـ محمد نور الدين، تركيا في الزمن المتحول قلق الهوية وصر اع الخيارات) بيروت، 1997) ،ص 44 


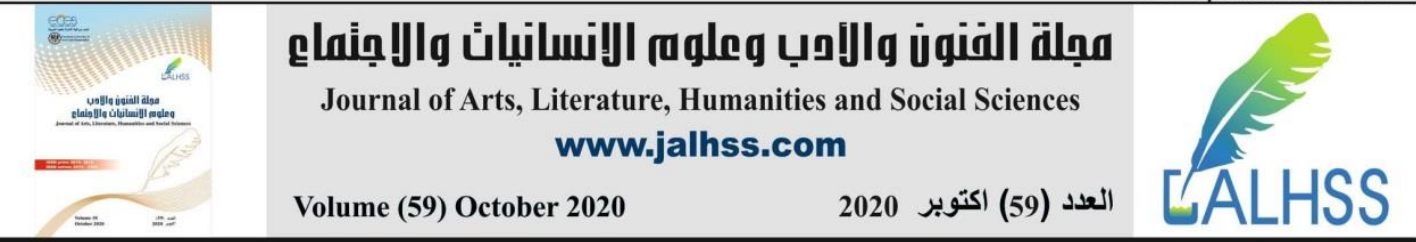

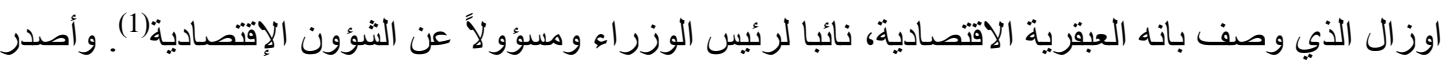

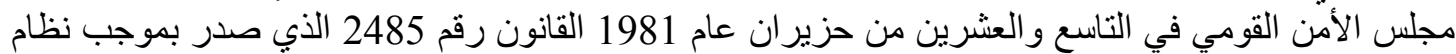

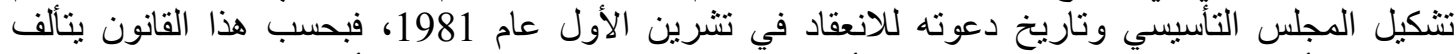

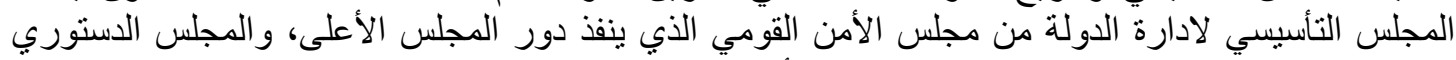

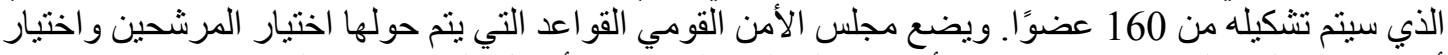

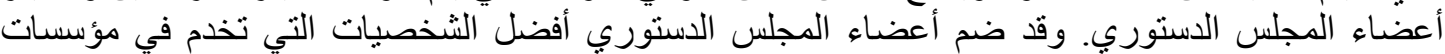
الدولة أو في القطاع الخاص.وفي الخامس عشر من تشرين الأول عام 1981 تم الإعلان عن تركيبة التانية المجلس

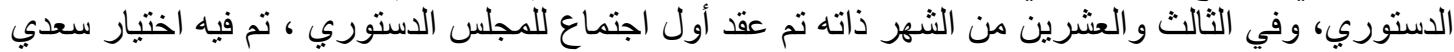

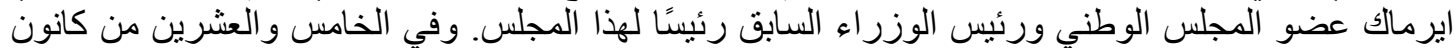

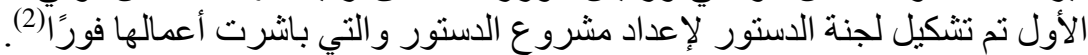

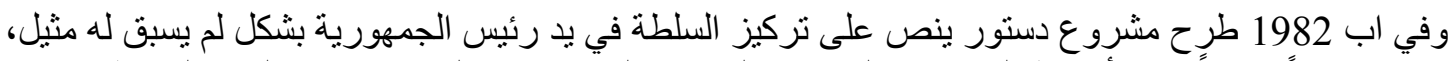

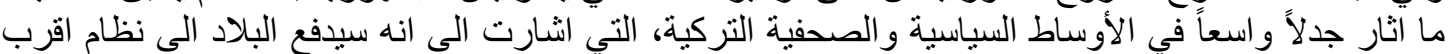

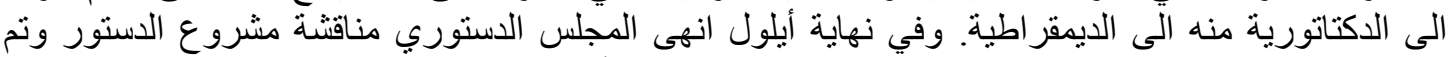

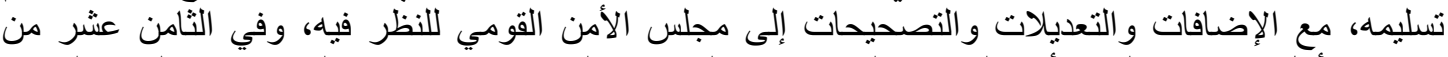

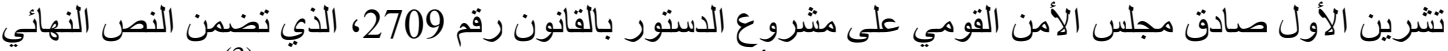

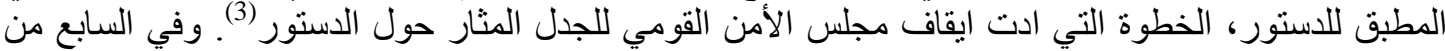

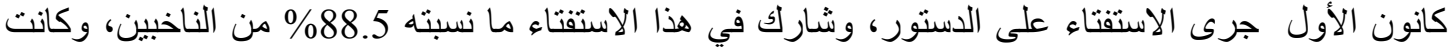

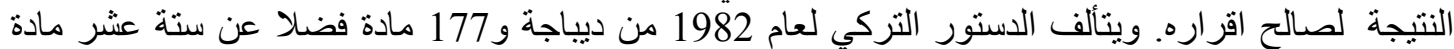

مؤقتة مقسمة على سبعة أجزاء (4).

وقد ذكر في ديباجته: بعد اتمام العملية التي قامت بها القوات المسلحة في الثاني عثر من أيلول عام 1980 أليكات

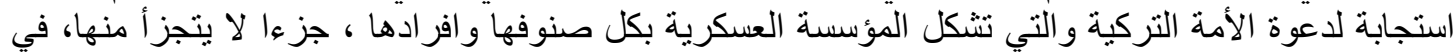

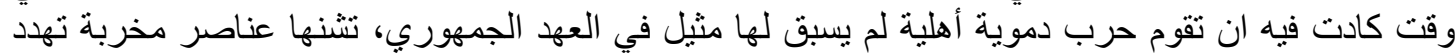

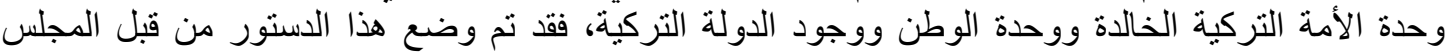

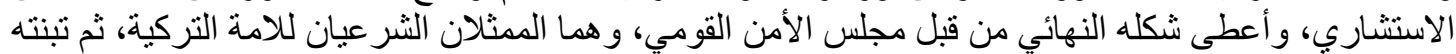

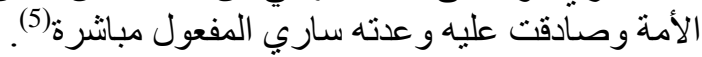

يبدو ان هذا الدستور قد اعطى لمجلس الامن القومي، والمؤسسة العسكرية كامل الصلاحيات اللامحدودة في

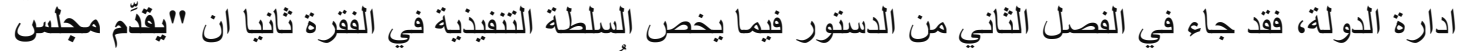

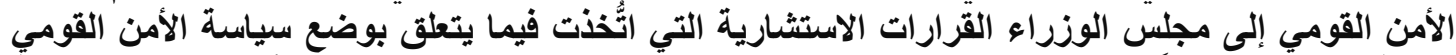

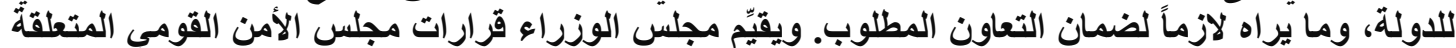

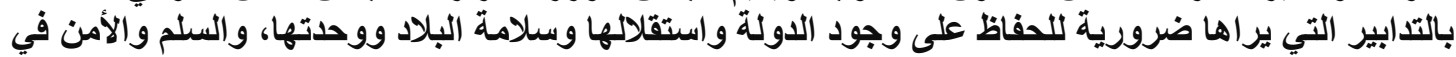

- نوبار هو بسبيان وآخرون، تركيا بين الصفوة البيروقر اطية و الحكم العسكري، إعداد سامي الرزاز و غانم بيبي، (1)

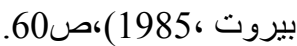

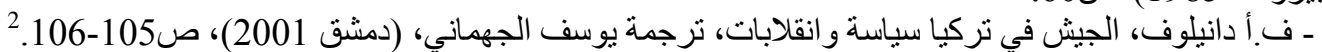
2-- Muhsin Batur,Op., Cit.,pp.182-183.

1-Bulut Gürpınar, “1982 Anayasası'na Göre Milli Güvenlik Kavramı”, Hasan Kalyoncu Üniversitesi Hukuk Fakültesi Dergisi, ( Aralık 2012), pp.124-148.

، دستور تركيا الصادر عام 1982 شاملا تعديلاته لغاية عام 2011، constituteproject.org -2 https://www. ترجمة المؤسسة الدولية للايمقر اطية و الانتخابات، https://www.constituteproject.org/constitution/Turkey_2011.pdf?lang=ar ‘p8. 


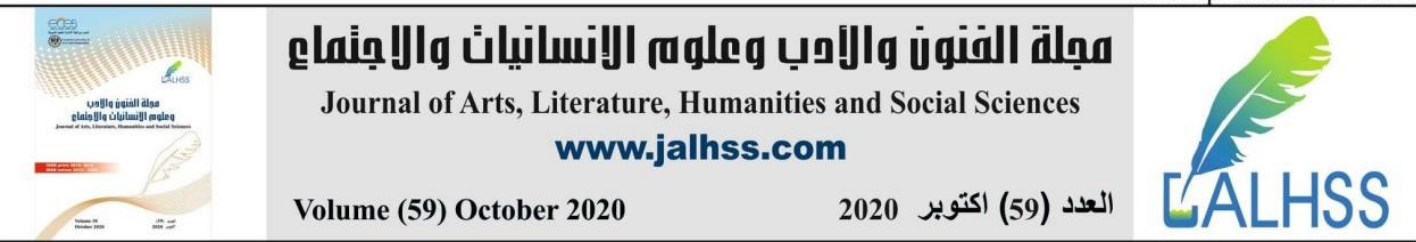

ويضع رئيس الجمهورية جدول أعمال مجلس الأمن القومي، مع أخذ مقترحات رئيس الوزراء ورئيس الأيس الأركان

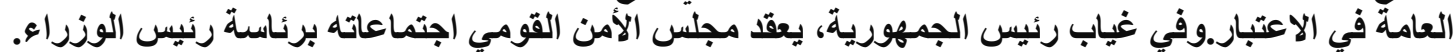

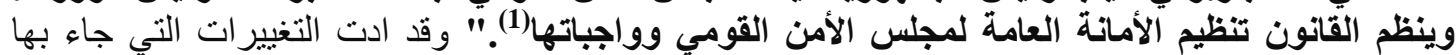

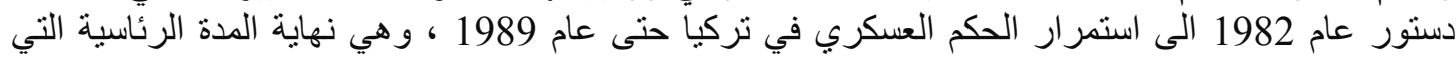
شغلها كنعان ايفرين قائد الانقلاب العسكري.

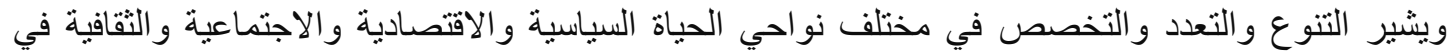

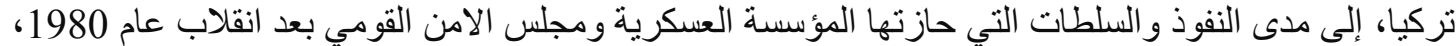

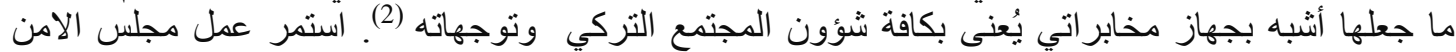

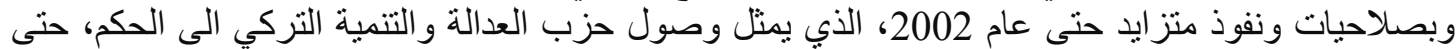

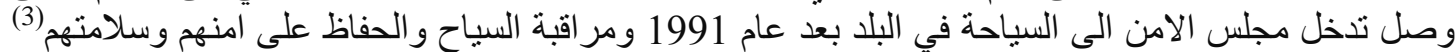

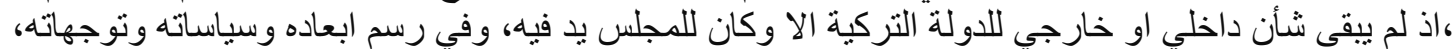
وشمل ذلك مختلف القضايا السياسية و الاقتصادية والاجتماعية والثانية الافية.

\section{مجلس الامن والسياسة الخارجية}

لم يقتصر عمل مجلس الامن القومي على الداخل التركي بل ان صلاحياته تعدت ذللك الى القضايا الخارجية،

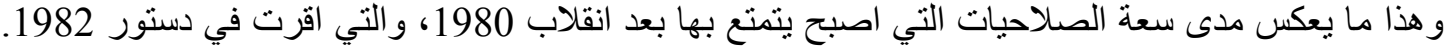

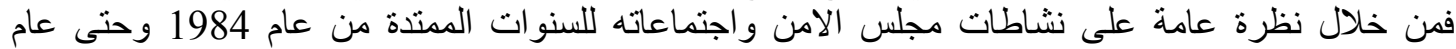

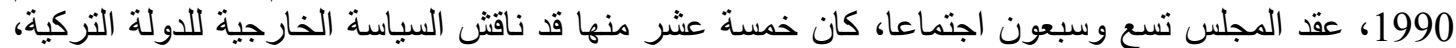

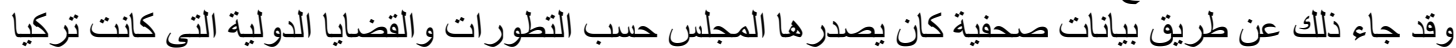

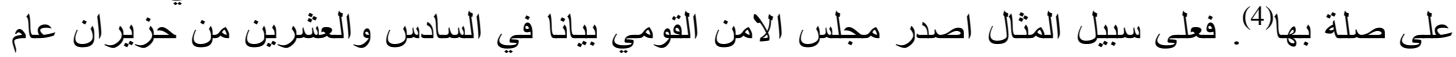

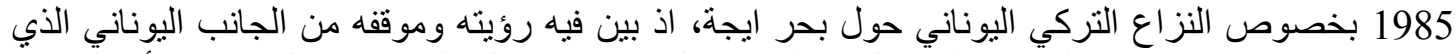

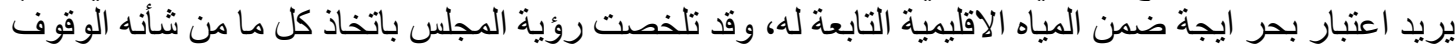

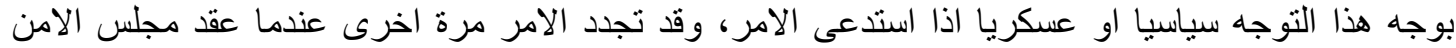

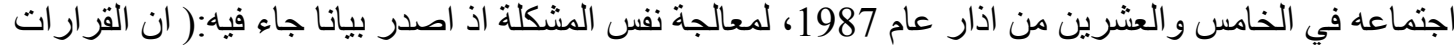

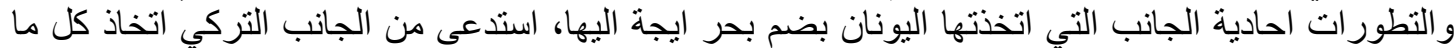

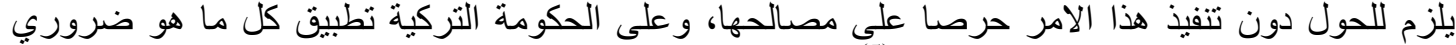

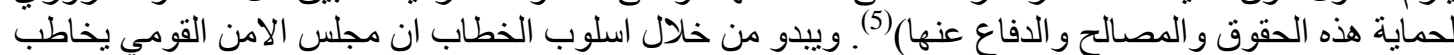

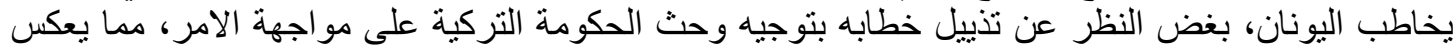

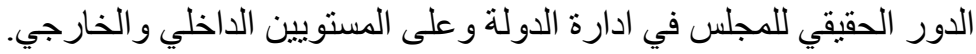

استمر مجلس الامن في توجيهاته للحكومة التركية في ما بخص سياسة الدولة الخارجية وقد ظهر هذئ هذا التوجيه

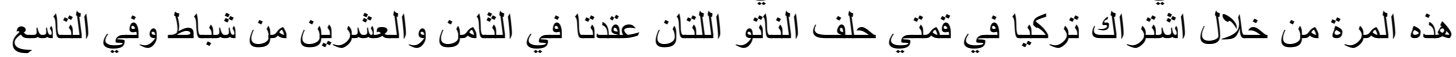

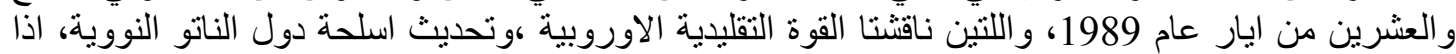

1-Bülent Tanör, İki Anayasa, 1961-1982,( İstanbul, 1986),p.56.

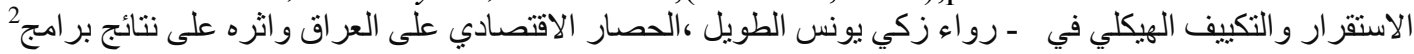

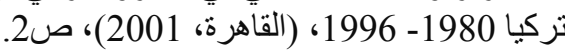

3- Bkz. http://www.mgk.gov.tr/Turkce/basinbildiri1997/2nisan1997.htm (Erişim Tarihi 31 A ğustos 2009).

4 - Arș. Gör., Op. Cit.,pp.83-84.

2. http://www.mgk.gov.tr/Turkce/basinbildiri1987/25mart1987.htm (Erişim Tarihi 31 Ağustos 2009). 


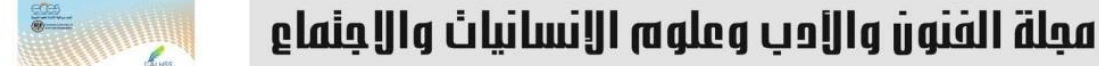 \\ Journal of Arts, Literature, Humanities and Social Sciences www.jalhss.com

طالب المجلس بشمول تركيا بهذا الامر، و الحرص على تقوية الترسانة العسكرية التركية، من خلال العمل على

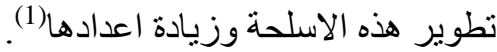

ازداد نشاط مجلس الامن القومي بالسياسة الخارجية في عقد التسعينيات من القرن العشرين، اذ شهدت السنوات التهات التهات

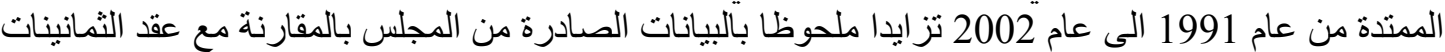

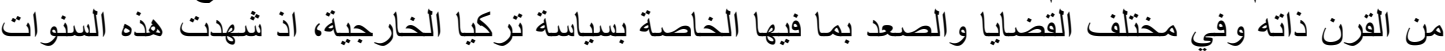

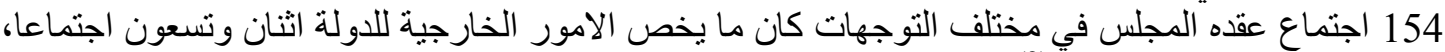

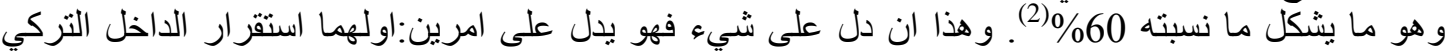

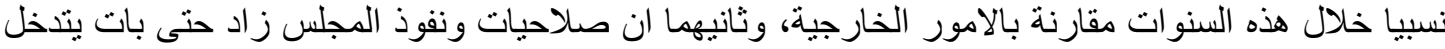

ويرسم ويوجه سياسة البلد الخارجية.

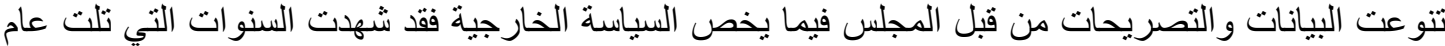

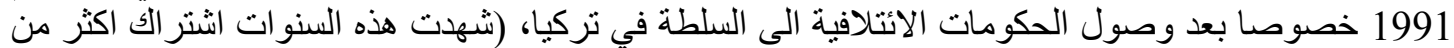

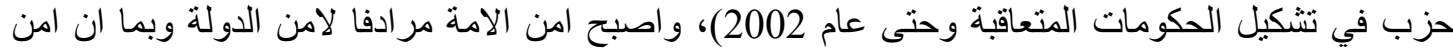

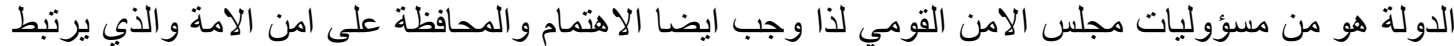

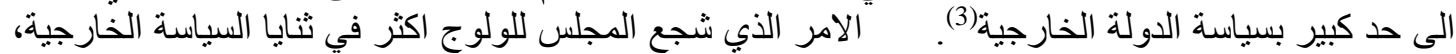

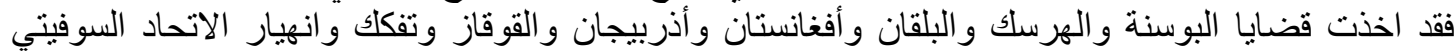

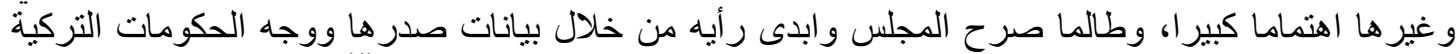

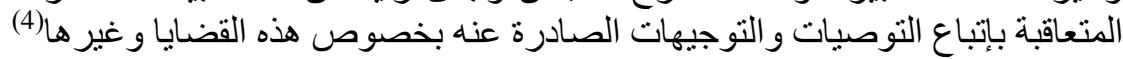

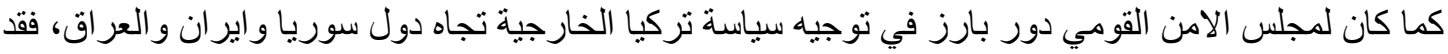

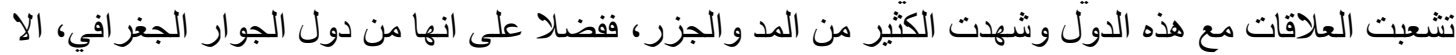

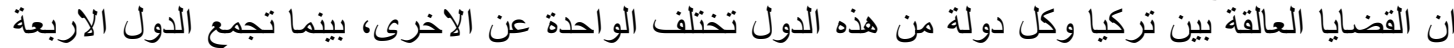

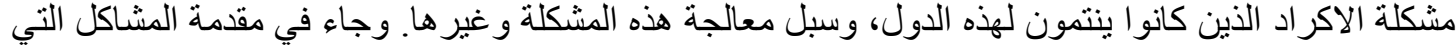

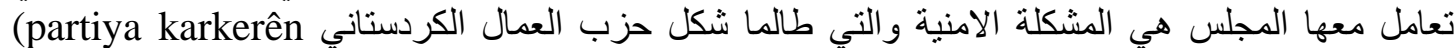

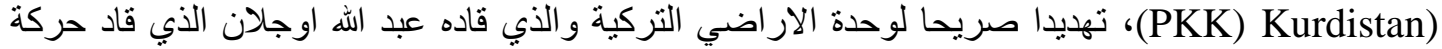

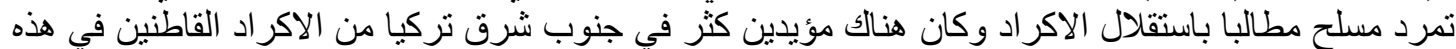

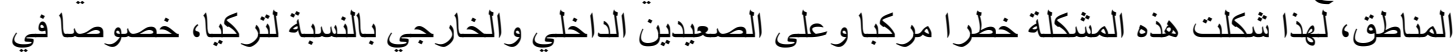

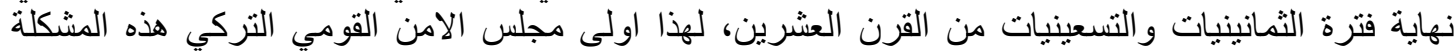

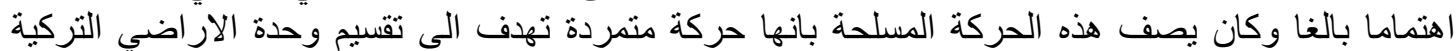

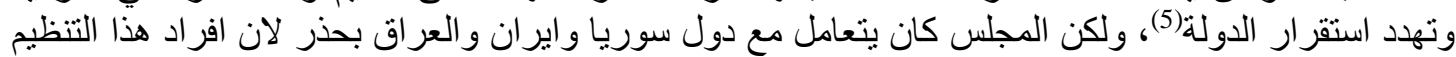

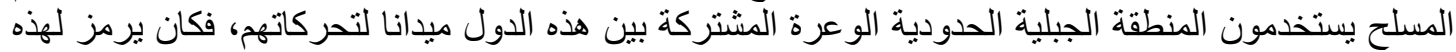

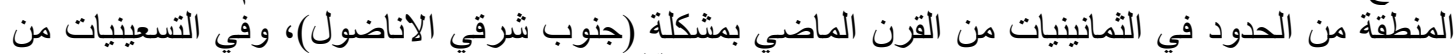

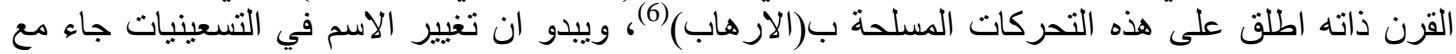

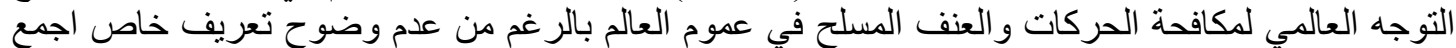

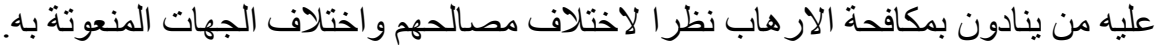

1_ http://www.mgk.gov.tr/Turkce/basinbildiri1989/26mayis1989.htm (Erişim Tarihi 31 A ğustos2009).

2- Arş. Gör.,Op.Cit.p.86.

${ }^{3-}$ Ibid.p.87.

1- Bkz. http://www.mgk.gov.tr/Turkce/basinbildiri1997/2nisan1997.htm (Erişim Tarihi 31 Ağustos 2009).

2- Kemali Saybaşılı’ya Armağan” Burak Ülman ve İsmet Akça (der.), İstanbul, 2006), p.364.( 1-Bkz. http://www.mgk.gov.tr/Turkce/basinbildiri1990/28mart1990.htm, (Erişim Tarihi 31 Ağustos 2009). 


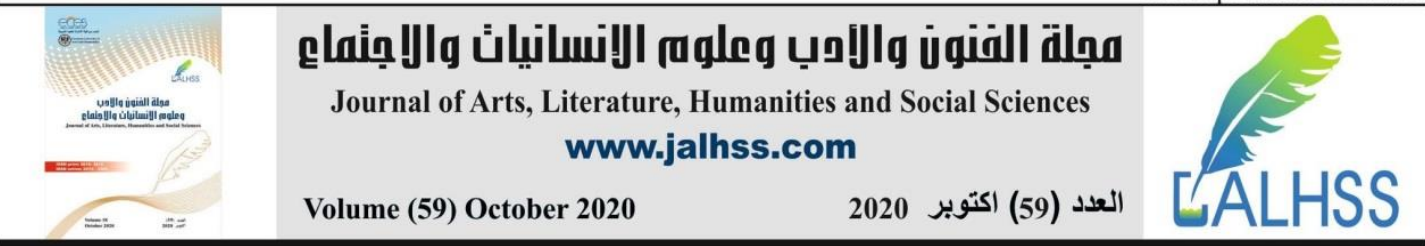

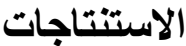

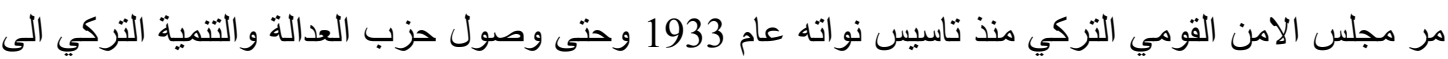

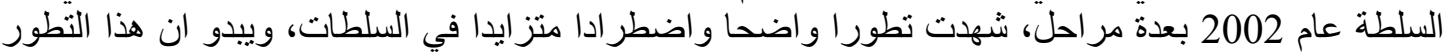

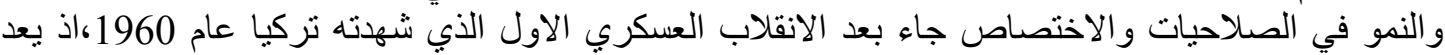

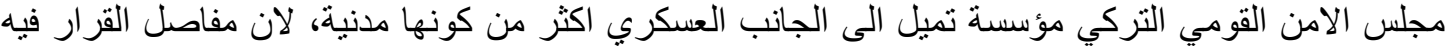

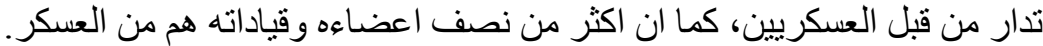

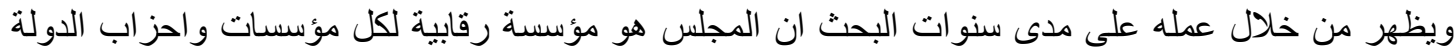

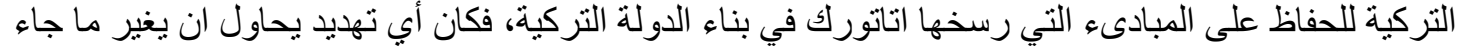

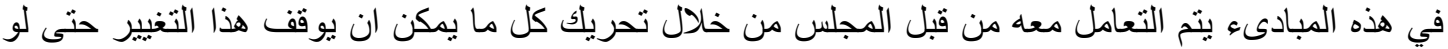

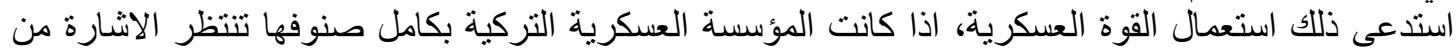

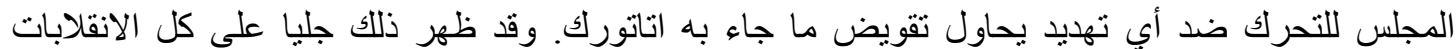
العسكرية التي شهدتها تركيا طو ال مدة البحث.

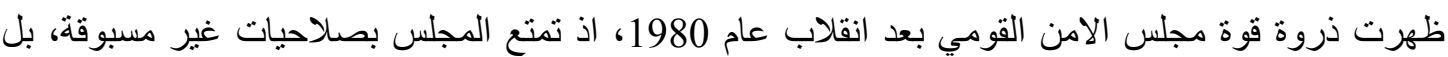

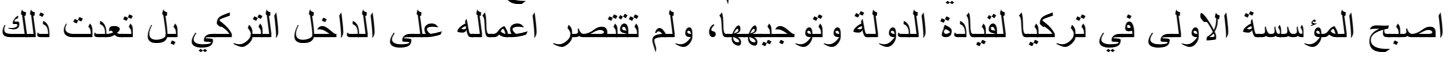

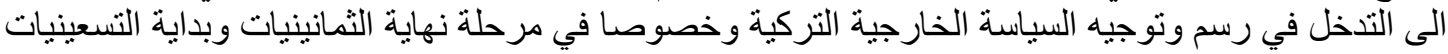

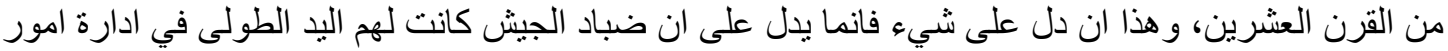

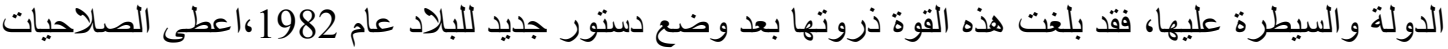

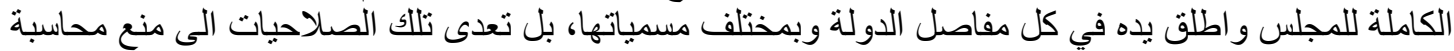

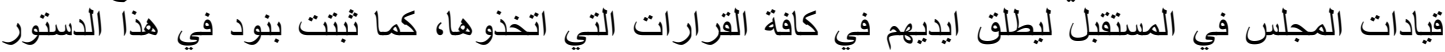

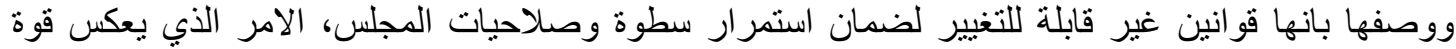
وسيطرة هذه المؤسسة على الدولة التركية وسياساتها الداخلية و الخارجية.

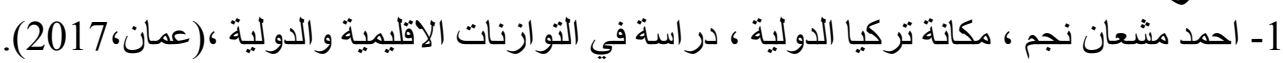

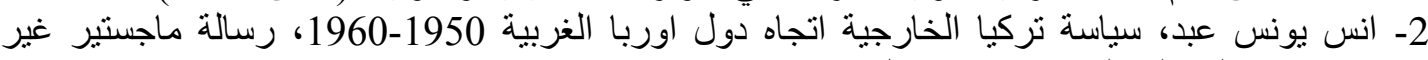

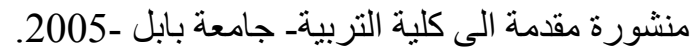
3- حنا عزو بهنان، موقع رئيس الجمهورية في صنية الثع القرار في تركيا، مركز الدراسات الاقليمية، جامعة

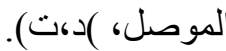
4- رضا هلال، السيف و الهلال تركيا من أناتورك إلى أربكان، (القاهرة، 1990).

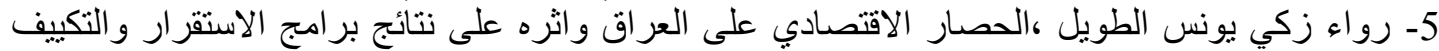

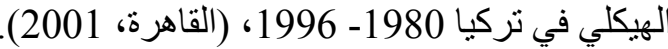
6- طلال يونس الجليلي، قراءة في أفكار النخبة السياسية التركية، (الموصل، 2006).

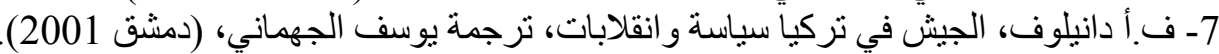

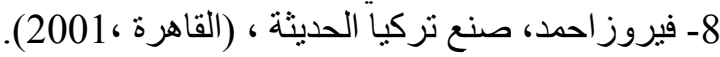

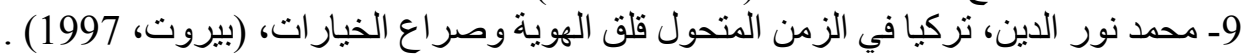

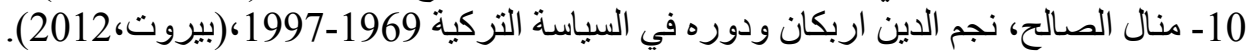

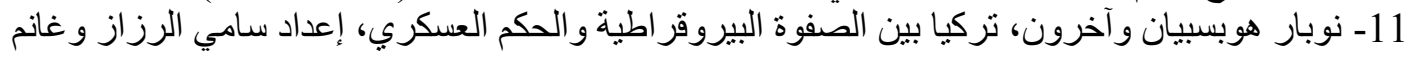

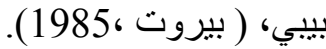




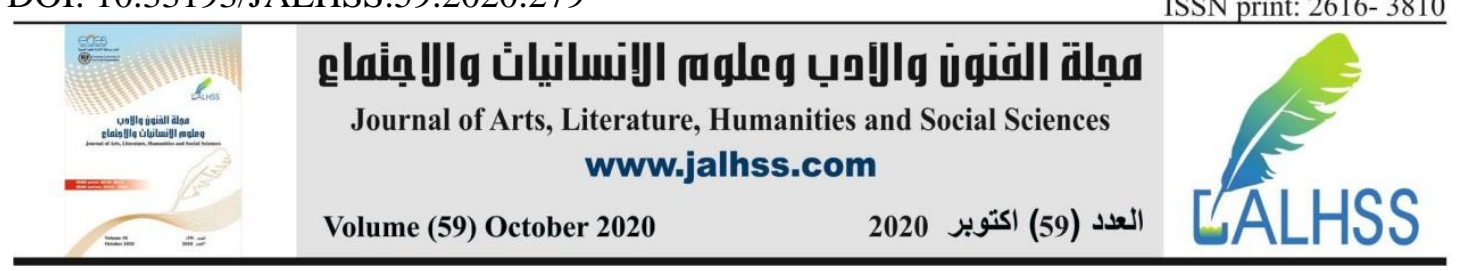

12- Arş. Gör., Milli Güvenlik Kurulu ve Diş Politika Bulut GÜRPINAR. Gebze Yüksek Teknoloji Enstitüsü, Strateji Bölümü,( Kocaeli,2013).

13-Bülent Tanör, İki Anayasa, 1961-1982,( İstanbul, 1986).

14-Bulut Gürpınar, “1982 Anayasası'na Göre Milli Güvenlik Kavramı”, Hasan

Kalyoncu Üniversitesi Hukuk Fakültesi Dergisi, ( Aralık 2012).

15- Hikmet Özdemir, Rejim ve Asker, (İstanbul, 1993).

16- Muharrem Balc1, MGK ve Demokrasi: Hukuk-Ordu-Siyaset, Yöneliş Yayınevi, (İstanbul 2000).

17- Muhsin Batur, Anılar ve Görüşler, “Üç Dönemin Perde Arkası”, (İstanbul, 1985).

18- Tayfun Akgüner, 1961 Anayasasına Göre Milli Güvenlik Kavramı ve Milli

Güvenlik Kurumu, İstanbul Üniversitesi SBF, 19XX.

19- Kemali Saybaşılı'ya Armağan” Burak Ülman ve İsmet Akça (der.), (İstanbul, 2006).

20- Bkz. http://www.mgk.gov.tr/Turkce/basinbildiri1997/2nisan1997.htm (Erişim

Tarihi 31 Ağustos 2009).

21-http://www.mgk.gov.tr/Turkce/basinbildiri1987/25mart1987.

htm (Erişim Tarihi 31 Ağustos 2009).

22- http://www.mgk.gov.tr/Turkce/basinbildiri1989/26mayis1989.

htm (Erişim Tarihi 31 Ağustos2009).

23- Bkz. http://www.mgk.gov.tr/Turkce/basinbildiri1997/2nisan1997.htm (Erişim

Tarihi 31 Ağustos 2009).

24- Bkz. http://www.mgk.gov.tr/Turkce/basinbildiri1990/28mart1990.

htm, (Erişim Tarihi 31 Ağustos 2009).

25-https://www.constituteproject.org/constitution/Turkey_2011.pdf?lang=ar 